\title{
Impact of previous exposure to systemic corticosteroids on unfavorable outcome in patients hospitalized for COVID-19
}

Margaux Lafaurie ${ }^{1,2^{*}}$ D, Guillaume Martin-Blondel ${ }^{3,4}$, Pierre Delobel ${ }^{3,4}$, Nassim Kamar ${ }^{5,6}$, Sandrine Charpentier ${ }^{7}$, Agnès Sommet ${ }^{1,2}$, Guillaume Moulis ${ }^{2,8}$ and and the Covid-Clinic-Toul investigators

\begin{abstract}
Background: The impact of prior exposure to systemic corticosteroids on COVID-19 severity in patients hospitalized for a SARS-CoV-2 pneumonia is not known. The present study was designed to answer to this question.

Methods: The population study was the Covid-Clinic-Toul cohort which records data about all hospitalized patients with a positive reverse transcriptase polymerase chain reaction for a SARS-CoV-2 infection at Toulouse University hospital, France. Exposure to systemic corticosteroids was assessed at hospital admission. A propensity score (PS) according to corticosteroid exposure was calculated including comorbidities, clinical, radiological and biological variables that impact COVID-19 severity. The primary outcome was composite, including admission to intensive care unit, need of mechanical ventilation and death occurring during the 14 days after hospital admission. Logistic regression models adjusted for the PS (overlap weighting) provided odds ratios (ORs) and their 95\% confidence intervals (95\% Cls).

Results: Overall, 253 patients were included in the study. Median age was 64 years, 140 patients (59.6\%) were men and $218(86.2 \%)$ had at least one comorbidity. Seventeen patients (6.7\%) were exposed to corticosteroids before hospital admission. Chronic inflammatory disease $(n=8)$ was the most frequent indication. One hundred and twenty patients (47.4\%) met the composite outcome. In the crude model, the OR of previous exposure to systemic corticosteroids was 1.64; 95\% Cl: 0.60-4.44. In the adjusted model, it was 1.09 (95\% Cl: 0.65-1.83).

Conclusion: Overall, this study provide some evidences for an absence of an increased risk of unfavorable outcome with previous exposure to corticosteroids in the general setting of patients hospitalized for COVID-19.
\end{abstract}

Keywords: SARS-COV-2, COVID-19, Systemic corticosteroids, Mortality, Intensive care unit, Pharmacoepidemiology

\footnotetext{
* Correspondence: margaux.lafaurie@univ-tlse3.fr

${ }^{1}$ Service de Pharmacologie Médicale, Centre Hospitalier Universitaire de Toulouse, Faculté de Médecine, 37 allées Jules Guesde, 31000 Toulouse, France

${ }^{2}$ Centre d'investigation clinique 1436, axe pharmacoépidémiologie, Centre Hospitalier Universitaire de Toulouse-Purpan, place du Dr Baylac, TSA40031, 31059 Toulouse, Cedex 9, France

Full list of author information is available at the end of the article
}

(c) The Author(s). 2021 Open Access This article is licensed under a Creative Commons Attribution 4.0 International License, which permits use, sharing, adaptation, distribution and reproduction in any medium or format, as long as you give appropriate credit to the original author(s) and the source, provide a link to the Creative Commons licence, and indicate if changes were made. The images or other third party material in this article are included in the article's Creative Commons licence, unless indicated otherwise in a credit line to the material. If material is not included in the article's Creative Commons licence and your intended use is not permitted by statutory regulation or exceeds the permitted use, you will need to obtain permission directly from the copyright holder. To view a copy of this licence, visit http://creativecommons.org/licenses/by/4.0/ The Creative Commons Public Domain Dedication waiver (http://creativecommons.org/publicdomain/zero/1.0/) applies to the data made available in this article, unless otherwise stated in a credit line to the data. 


\section{Background}

Corticosteroid-based therapy is used to treat patients with severe coronavirus disease 2019 (COVID-19) to reduce inflammatory lung injury, notably when a major cytokine reaction is responsible for clinical worsening [1-4]. A recent prospective meta-analysis of clinical trials conducted by the World Health Organization (WHO) Rapid Evidence Appraisal for COVID-19 Therapies (REACT) Working Group showed that administration of systemic corticosteroids in critically ill patients with COVID-19, compared with usual care or placebo, was associated with lower 28-day all-cause mortality [5]. Moreover, exposure to systemic corticosteroids before COVID-19, responsible for immunosuppression, has been hypothesized to be associated with severe forms of COVID-19. Systemic exposure to corticosteroids has been associated with an increased risk of hospitalization in patients with rheumatic diseases $(\geq 10 \mathrm{mg} /$ day in prednisone-equivalent dosage, OR: 2.05 ; 95\% CI: $1.06-$ 3.96) [6]. A major increased risk of severe COVID-19 (defined by admission in intensive care unit - ICU, need of mechanical ventilation or death) was found in patients with chronic inflammatory bowel disease (OR: 6.9; 95\% CI: 2.3-20.5) [7]. These studies were focused on patients with some autoimmune diseases and were not adjusted for clinical, biological and radiological markers of COVID-19 severity. The impact of previous exposure to corticosteroids in the general setting of patients hospitalized for COVID-19 is unknown.

We aimed to assess the impact of prior exposure to systemic corticosteroids on COVID-19 severity in patients hospitalized for reverse transcriptase polymerase chain reaction (RT-PCR)-proven SARS-CoV-2 infection.

\section{Methods}

\section{Study population}

The study was conducted within the Covid-Clinic-Toul cohort which records data about all hospitalized patients with a positive RT-PCR for a SARS-CoV-2 infection at Toulouse University hospital, France $[8,9]$. This cohort has been approved by institutional review board ( $n^{\circ} \mathrm{RnIPH} 2020-31$ ), in accordance with French law. All patients, or their representatives, were informed by a letter given at admission to hospital and/or sent to their place of residency. Exclusion criterion was opposition to data collection. We selected the patients included up to April 20, 2020 and with a chest computed tomography (CT) scan at admission. Patients from April 1st were prospectively included.

\section{Exposure}

Exposure to systemic corticosteroid at hospital admission was assessed by physicians and then extracted from electronic medical records. Drug, dosage, duration of use (categorized as short-term exposure for $<7$ days vs $\geq$ 7 days) and indication were described.

\section{Outcome}

The primary outcome was composite, including admission to ICU, need of mechanical ventilation and death occurring during the 14 days after hospital admission.

\section{Covariables}

The following variables were assessed at hospital admission: age ( $\geq 65$ years vs. $<65$ years), sex, presence of hypertension, cardiovascular disease, cerebrovascular disease, chronic pulmonary disease, chronic liver disease, chronic kidney disease, diabetes, cancer, overweight, immunosuppression (excluding exposure to corticosteroids), oxygen saturation $\leq 92 \%$ or need of oxygen therapy, lymphopenia $(<1.5 \times 109 / \mathrm{L})$, thrombocytopenia $(<150 \times 109 / \mathrm{L})$, C-reactive protein $(\geq 50$ $\mathrm{mg} / \mathrm{L}$ vs. $<50 \mathrm{mg} / \mathrm{L})$, extension of ground glass opacities at chest CT-scan categorized by absence or mild involvement $(<25 \%$ of lung parenchyma) vs. moderate to critical involvement $(\geq 25 \%)$.

\section{Statistical analyses}

For descriptive analyses, continuous variables were expressed by mean and standard deviation or median and interquartile range (IQR) depending on their distribution, and categorical variables by percentages. For comparatives analyses, multiple imputation $(n=5)$ was used to handle missing values [10]. A propensity score (PS) was calculated based on the covariables listed above [11]. Analyses were conducted using logistic regression models and were adjusted with overlap weighting (OW) on the PS, providing odds ratios (ORs) and their 95\% confidence intervals (95\% CIs) [12]. OW allows adjustment in population with large differences in covariables, by emphasizing the target population with the most overlap in observed characteristics between exposed and unexposed patients, and down-weighting the tails units. Exposed patients were weighted by the probability of not receiving corticosteroids (1 - PS) and unexposed patients were weighted by the probability of receiving corticosteroids (PS) [13]. Statistical analyses were performed using SAS V9.4 ${ }^{\text {тм }}$ (SAS institute, Cary, NC, USA).

\section{Results}

\section{Study population}

Overall, 253 patients were included in the study. Characteristics of the patients are presented in Table 1. Median age was 64 years (IQR: 54-76), 140 patients (59.6\%) were men, and $218(86.2 \%)$ presented at least one comorbidity. The median duration of symptoms at the time of admission to hospital was 7 days (IQR: 4-10). 
Table 1 Characteristics of the patients hospitalized for COVID-19 included in the study $(n=253)$

\begin{tabular}{|c|c|c|c|c|c|}
\hline & \multirow[t]{2}{*}{$\begin{array}{l}\text { Total } \\
(n=253)\end{array}$} & \multicolumn{2}{|c|}{ Exposure to corticosteroids } & \multicolumn{2}{|c|}{$\begin{array}{l}\text { Admission to ICU, mechanica } \\
\text { ventilation, or death during } \\
\text { the first } 14 \text { days }\end{array}$} \\
\hline & & $\begin{array}{l}\text { No } \\
(n=236)\end{array}$ & $\begin{array}{l}\text { Yes } \\
(n=17)\end{array}$ & $\begin{array}{l}\text { No } \\
(n=133)\end{array}$ & $\begin{array}{l}\text { Yes } \\
(n=120)\end{array}$ \\
\hline \multicolumn{6}{|l|}{ Age (years) } \\
\hline Median (IQR) & $65(54-76)$ & $64(54-76)$ & $73(62-82)$ & $62(50-75)$ & $68(58-78)$ \\
\hline$\geq 65$ years, $n(\%)$ & $128(50.6)$ & $117(49.6)$ & $11(64.7)$ & $59(44.4)$ & $69(57.5)$ \\
\hline \multicolumn{6}{|l|}{ Sex } \\
\hline Male, n (\%) & $150(59.3)$ & $141(59.7)$ & $9(52.9)$ & $69(51.9)$ & $81(67.5)$ \\
\hline Female, n (\%) & $103(40.7)$ & $95(40.3)$ & $8(47.1)$ & $64(48.1)$ & $39(32.5)$ \\
\hline \multicolumn{6}{|l|}{ Comorbidities } \\
\hline$\geq 1$ comorbidity, n (\%) & $218(86.2)$ & $201(85.2)$ & $17(100)$ & $111(83.5)$ & $107(89.2)$ \\
\hline Overweight, (BMI: $25-30$ kg/m²), n (\%) & $85(36.2)$ & 79 (35.6) & $6(46.2)$ & $43(36.1)$ & $42(36.2)$ \\
\hline Obesity, (BMI $\geq 30$ kg/m²), n (\%) & $68(28.9)$ & $65(29.3)$ & $3(23.1)$ & $28(23.5)$ & $40(34.5)$ \\
\hline Hypertension, n (\%) & $102(40.3)$ & $92(39.0)$ & $10(58.8)$ & $46(34.6)$ & $56(46.7)$ \\
\hline Heart failure, n (\%) & $10(4.0)$ & $9(3.8)$ & $1(5.9)$ & $5(3.8)$ & $5(4.2)$ \\
\hline History of coronary disease, n (\%) & $24(9.5)$ & $20(8.5)$ & $4(23.5)$ & $9(6.8)$ & $15(12.5)$ \\
\hline History of cardiac surgery, n (\%) & $3(1.2)$ & $2(0.9)$ & $1(5.9)$ & $2(1.5)$ & $1(0.8)$ \\
\hline History of cerebrovascular disease, $\mathrm{n}(\%)$ & $16(6.3)$ & $14(6.0)$ & $2(11.8)$ & $8(6.0)$ & $8(6.7)$ \\
\hline Diabetes, n (\%) & 49 (19.4) & $43(18.2)$ & $6(35.3)$ & $20(15.0)$ & $29(24.2)$ \\
\hline Chronic lung disease, n (\%) & $54(21.3)$ & $45(19.7)$ & $9(52.9)$ & $24(18.1)$ & $30(25.0)$ \\
\hline Chronic kidney disease, n (\%) & $23(9.1)$ & $19(8.1)$ & $4(23.5)$ & $11(8.3)$ & $12(10.0)$ \\
\hline Chronic liver disease, n (\%) & $2(0.8)$ & $1(0.4)$ & $1(5.9)$ & $0(0)$ & $2(1.7)$ \\
\hline Malignancy, n (\%) & $27(10.7)$ & $22(9.3)$ & $5(29.4)$ & $12(9.0)$ & $15(12.5)$ \\
\hline Immunosuppression, n (\%) & $20(7.9)$ & $10(4.2)$ & $10(58.8)$ & $8(6.0)$ & $12(10.0)$ \\
\hline Time between first symptoms and hospital admission, median (IQR) ${ }^{a}$ & $7(4-10)$ & $7(5-10)$ & $4(2-4)$ & $7(4-10)$ & $7(4-9)$ \\
\hline \multicolumn{6}{|l|}{ At hospital admission } \\
\hline Oxygen saturation $\leq 92 \%$ or need of oxygen therapy, $n(\%)^{a}$ & $116(46.2)$ & $110(46.8)$ & $6(37.5)$ & $33(25.0)$ & $83(69.8)$ \\
\hline C-reactive protein level, $>50 \mathrm{mg} / \mathrm{L}, \mathrm{n}(\%)^{a}$ & $129(51.8)$ & $122(52.6)$ & $7(41.2)$ & $53(39.9)$ & $76(65.5)$ \\
\hline Platelets count, $<150 \times 10^{9} / \mathrm{L}, \mathrm{n}(\%)^{\mathrm{a}}$ & $63(25.3)$ & $58(25.0)$ & $5(29.4)$ & $20(15.3)$ & $43(36.4)$ \\
\hline Lymphocytes, $<1.5 \times 10^{9} / \mathrm{L}, \mathrm{n}(\%)^{\text {a }}$ & $185(83.0)$ & $173(83.2)$ & $12(80.0)$ & $84(74.3)$ & $101(91.8)$ \\
\hline \multicolumn{6}{|l|}{ Chest CT-scan severity score } \\
\hline Absence or mild, $n(\%)$ & $44(17.4)$ & $42(17.8)$ & $2(11.8)$ & $27(20.3)$ & $17(14.2)$ \\
\hline Moderate, severe, or critical, n (\%) & $209(82.6)$ & $194(82.2)$ & $15(88.2)$ & $106(79.7)$ & $103(85.8)$ \\
\hline Exposure to corticosteroids, $\mathrm{n}(\%)$ & $17(6.7)$ & - & $17(100)$ & $7(5.3)$ & $10(8.3)$ \\
\hline Composite outcome, n (\%) & $120(47.4)$ & $110(46.6)$ & $10(58.8)$ & - & $120(100)$ \\
\hline Admission to ICU, n (\%) & $109(43.1)$ & $102(43.2)$ & $7(41.2)$ & - & 109 (90.8) \\
\hline Mechanical ventilation, n (\%) & $61(24.1)$ & $58(24.6)$ & $3(17.7)$ & - & $61(50.8)$ \\
\hline Death, n (\%) & $19(7.5)$ & $14(5.9)$ & $5(29.4)$ & - & $19(15.8)$ \\
\hline
\end{tabular}

Abbreviations: $B M I$ body mass index, $C T$ computed tomography, ICU intensive care unit, IQR interquartile range

${ }^{a}$ Missing data: body mass index, $n=18$; time between first symptoms and hospital admission, $\mathrm{n}=2$; oxygen saturation, $\mathrm{n}=2 ; \mathrm{C}$-reactive protein, $\mathrm{n}=2$, platelets count, $\mathrm{n}=4$; lymphocytes, $n=30$

\section{Exposure to corticosteroids}

Seventeen patients (6.7\%) were exposed to corticosteroids before hospital admission. Their characteristics are presented in Table 2. The most frequent corticosteroid was prednisone $(n=9)$. Fifteen patients $(83.3 \%)$ had an exposure to corticosteroids $\geq 7$ days; indications were chronic inflammatory disease $(n=8)$, solid organ transplantation $(n=4)$ and malignancies $(n=4)$. As compared 


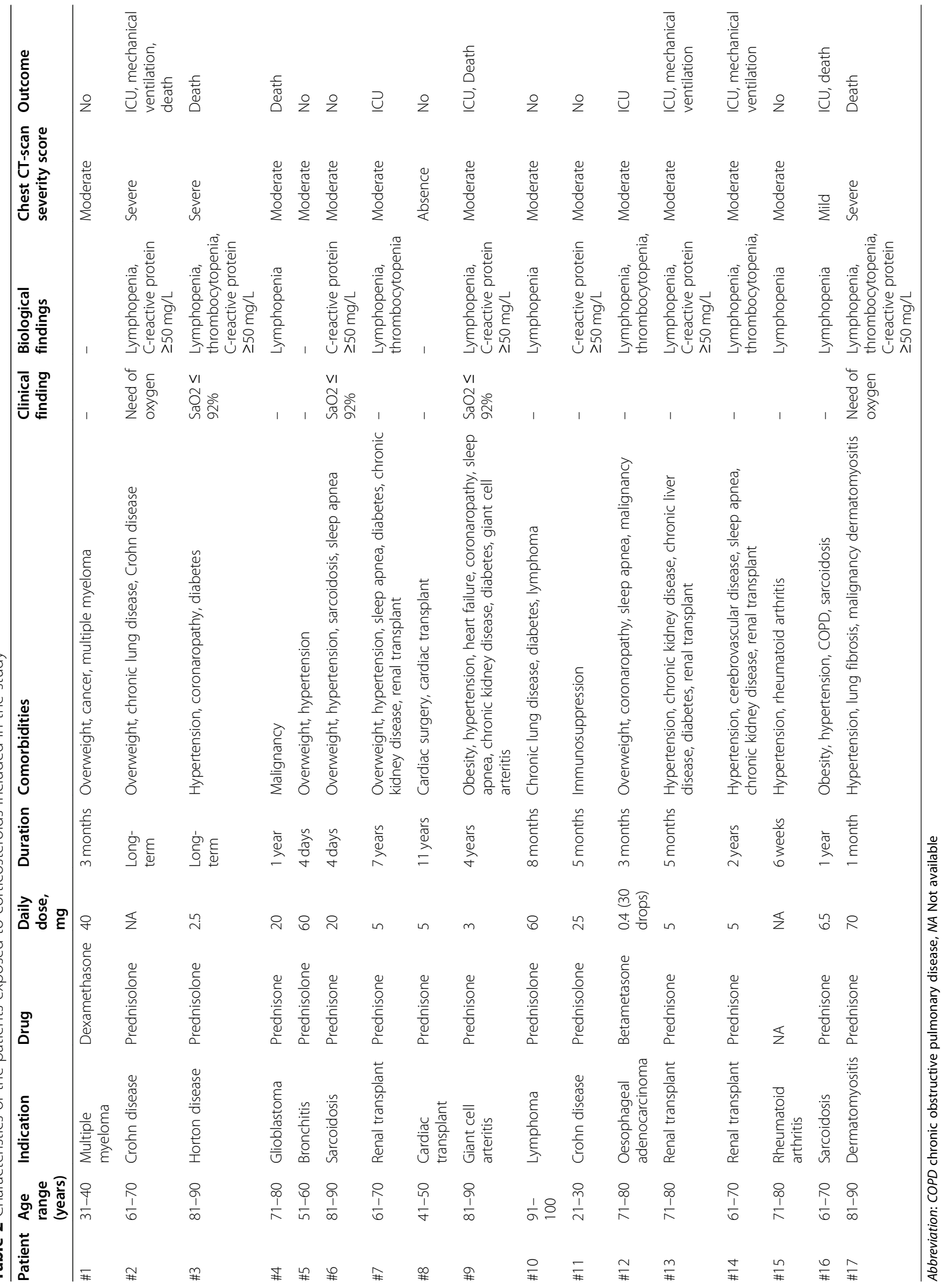


with non-exposed patients, those exposed to corticosteroids were older ( $\geq 65$ years: $64.7 \%$ vs $49.6 \%$ ), with a cause of immunosuppression ( $58.8 \%$ vs $4.2 \%$ ), chronic lung disease (52.9\% vs $19.7 \%)$ and hypertension $(58.8 \%$ vs $39.0 \%)$. However, clinical, radiological, and biological markers of COVID-19 severity at hospital admission were comparable between the two groups (Table 1).

\section{Outcome}

One hundred and twenty patients (47.4\%) met the composite outcome during the first 14days of hospitalization; 61 (24.1\%) required mechanical ventilation and 19 (7.5\%) died (Table 1). The median time between admission and outcome occurrence was 1 day (IQR: $0-3$ days). Ten patients exposed to corticosteroids (58.8\%), all with an exposure $\geq 7$ days, met the composite outcome (Table 2).

\section{Comparative analyses}

In the crude model, the OR of exposure to systemic corticosteroid at the time of admission to hospital with outcome occurrence was 1.64; 95\% CI: 0.60-4.44. The PS distribution is presented in Supplementary Fig. S1. The PS was efficient in establishing balance for each covariable (data not shown). In the adjusted model with OW on the PS, the OR was 1.09 (95\% CI: 0.65-1.83).

\section{Discussion}

In this study, we found a trend for an increased risk of poor outcome in COVID-19 hospitalized patients in case of previous exposure to corticosteroid before hospital admission. However, after adjustment for potential confounders, we found no evidence for an increased risk. This result differs from the two previously quoted studies in patients with rheumatic disease or chronic inflammatory bowel disease $[6,7]$. However, these were other settings, with no adjustment for other COVID-19 severity markers at the time of admission. Moreover, in the study conducted in patients with chronic inflammatory bowel disease, comorbidities were included quantitatively [7]. However, some comorbidities are expected to be more related with both exposure to corticosteroids and disease severity. That's why we included each comorbidity in the PS calculation. Of note, patients exposed to corticosteroids in our cohort had more frequently chronic lung disease, hypertension, and cause of immunosuppression only.

This study conducted in the Covid-Clinic-Toul cohort presented strengths. The cohort is a clinical cohort with most of the data prospectively collected. Exposure to systemic corticosteroids was exhaustively assessed for each patient. Missing values were very rare and handled by multiple imputation. Adjustment using OW on the PS provided risk estimation by minimizing confusion bias due to important differences in the characteristics between exposed and unexposed patients.

Our study had several limitations. Data were restricted to a single hospital center. Only $6.7 \%(n=17)$ of the patients were exposed to corticosteroids before hospital admission. This low sample size limited the interpretation of the results. Therefore, we could have only detected a major effect of corticosteroids on unfavorable outcome. Subgroup analyses by corticosteroids dosage, duration of exposure, and indications cannot be conducted due to this low number of exposed patients. Of note, 8 of the exposed patients $(47 \%)$ in our cohort had a daily prednisone equivalent dosage $<10 \mathrm{mg}$, which was not associated with an increased rate of hospitalization in the study in patients with rheumatic disease [6]. Because previous exposure to systemic corticosteroids is strongly associated with their indication and because subgroups analyses were not possible, results need to be interpreted cautiously. Finally, we cannot exclude the presence of unmeasured confounding factors like smoking. However, these factors are certainly related to comorbidities included in the PS and it is not clear whether they impact COVID-19 severity.

\section{Conclusion}

Overall, this study provide some evidences for an absence of an increased risk of unfavorable outcome with previous exposure to corticosteroids in the general setting of patients hospitalized for COVID-19.

\section{Abbreviations}

CT: Computed tomography; ICU: Intensive care unit; OW: Overlap weighting; PS: Propensity score; RT-PCR: reverse transcriptase polymerase chain reaction

\section{Supplementary Information}

The online version contains supplementary material available at https://doi. org/10.1186/s40360-021-00480-3.

Additional file 1: Figure S1. Propensity score distribution according to exposure to systemic corticosteroids prior to hospitalization by each imputation of missing data (5 imputations, panels A to E) in the study population $(n=253)$. Blue bars: patients unexposed to systemic corticosteroids. Red bars: patients exposed to systemic corticosteroids.

\section{Acknowledgments \\ The authors deeply thank Christophe Morin, Gaëlle Barencourt, Caroline Hurault-Delarue, Charlotte Vert and Julien Jacquot for their help in data ac- quisition and Isabelle Olivier for reglementary aspects.}

\section{Authors' contributions}

M.L., A.S. and G.M. designed the study. M.L. carried out the data management, conducted the statistical analysis and wrote the manuscript. M.L., G. M-B., P.D., N.K., S.C., A.S., G.M. and the collaborators included in the "Covid-clinic-Toul investigators group" included the patients and participated to data collection. M.L., G.M-B., P.D., N.K., S.C., A.S., G.M. interpreted the results, critically reviewed the manuscript and gave final approval for submission. M.L., G.M-B., P.D., N.K., S.C., A.S., G.M. also had full access to all of the data (including statistical reports) in the study and can take responsibility for the integrity of the data and the accuracy of the data analysis. 
Funding

The Covid-Clinic-Toul cohort is funded by Toulouse University hospital.

\section{Availability of data and materials}

The data that support the findings of this study are available on request from the corresponding author. The data are not publicly available due to privacy and ethical restrictions. The data management and statistical analysis code is available on request from the corresponding author.

\section{Declarations}

\section{Ethics approval and consent to participate}

The observational Covid-Clinic-Toul cohort has been approved by the of the Toulouse University Hospital Center review board ( ${ }^{\circ} \mathrm{Rn} I \mathrm{PH} 2020-31$ ) in accordance with the French data protection authority (MR004, Commission Nationale de l'Informatique et des Libertés, CNIL). The study was also registered on the INDS (Institut National des Données de Santé) registry, reference MR0515100420. According to French law and to the European General Data Protection Regulation, because of the pure real-life observational design, patients, or if not possible their representatives, had to receive an information form explaining the study and their rights notably as regards possibility of opposition to data collection. According to the same regulations, signed consent is not mandatory. All patients included in the observational Covid-Clinic-Toul cohort, or their representatives, were informed by a letter given at hospital admission and/or sent to their residency. Information of all patients is indicated in their medical files. Exclusion criterion was opposition to data collection.

\section{Consent for publication}

Not applicable.

\section{Competing interests}

None declared.

\section{Author details}

'Service de Pharmacologie Médicale, Centre Hospitalier Universitaire de Toulouse, Faculté de Médecine, 37 allées Jules Guesde, 31000 Toulouse, France. ${ }^{2}$ Centre d'investigation clinique 1436, axe pharmacoépidémiologie, Centre Hospitalier Universitaire de Toulouse-Purpan, place du Dr Baylac, TSA40031, 31059 Toulouse, Cedex 9, France. ${ }^{3}$ Service des Maladies Infectieuses et Tropicales, Centre Hospitalier Universitaire de Toulouse-Purpan, place du Dr Baylac, TSA40031, 31059 Toulouse, Cedex 9. France. ${ }^{4}$ UMR INSERM/CNRS 1043, Centre de Physiopathologie Toulouse Purpan, 330 avenue de Grande-Bretagne, 31059 Toulouse, Cedex 9, France. ${ }^{5}$ Service de Néphrologie et Transplantation d'Organes, Centre Hospitalier Universitaire de Toulouse-Rangueil, 1, avenue du Professeur Jean Poulhès TSA 50032, 31059 Toulouse cedex 9, France. ${ }^{6}$ INSERM U1043, IFR -BMT, Université Paul Sabatier, Toulouse, France. ${ }^{7}$ Service des Urgences, Centre Hospitalier Universitaire de Toulouse, Toulouse, France. ${ }^{8}$ Service de Médecine Interne, salle Le Tallec, Centre Hospitalier Universitaire de Toulouse-Purpan, place du Dr Baylac, TSA40031, 31059 Toulouse, Cedex 9, France.

Received: 25 September 2020 Accepted: 24 February 2021 Published online: 11 March 2021

\section{References}

1. Lu X, Chen T, Wang Y, et al. Adjuvant corticosteroid therapy for critically ill patients with COVID-19. Crit Care. 2020;24:241. https://doi.org/10.1186/s13 054-020-02964-w.

2. Jamilloux $Y$, Henry $T$, Belot $A$, et al. Should we stimulate or suppress immune responses in COVID-19? Cytokine and anti-cytokine interventions. Autoimmun Rev. 2020;19:102567. https://doi.org/10.1016/j.autrev.2020.102567.

3. McGonagle D, Sharif K, O'Regan A, et al. The role of cytokines including Interleukin-6 in COVID-19 induced pneumonia and macrophage activation syndrome-like disease. Autoimmun Rev. 2020;19:102537. https://doi.org/10.1 016/j.autrev.2020.102537.

4. RECOVERY Collaborative Group, Horby P, Lim WS, et al. Dexamethasone in Hospitalized Patients with Covid-19 - Preliminary Report. N Engl J Med Published Online First: 17 July 2020. https://doi.org/10.1056/NEJMoa2021436.

5. WHO Rapid Evidence appraisal for COVID-19 therapies (REACT) working group, JAC S, Murthy S, et al. Association between Administration of
Systemic Corticosteroids and Mortality among Critically ill Patients with COVID-19: a meta-analysis. JAMA. 2020;324:1330-41. https://doi.org/10.1001/ jama.2020.17023.

6. Gianfrancesco M, Hyrich KL, Al-Adely S, et al. Characteristics associated with hospitalisation for COVID-19 in people with rheumatic disease: data from the COVID-19 global rheumatology Alliance physician-reported registry. Ann Rheum Dis. 2020;79:859-66. https://doi.org/10.1136/annrheumdis-2020-217871.

7. Brenner EJ, Ungaro RC, Gearry RB, et al. Corticosteroids, but not TNF Antagonists, are Associated with Adverse COVID-19 Outcomes in Patients With Inflammatory Bowel Diseases: Results from an International Registry. Gastroenterology Published Online First: 18 May 2020. https://doi.org/10.1 053/j.gastro.2020.05.032.

8. Jourdes A, Lafaurie M, Martin-Blondel G, et al. Clinical characteristics and outcome of hospitalized patients with SARS-CoV-2 infection at Toulouse University hospital (France). Results from the Covid-clinic-Toul cohort. Rev Med Interne Published Online First: 7 October 2020. https://doi.org/10.1016/ j.revmed.2020.08.006.

9. Lafaurie M, Martin-Blondel G, Delobel P, et al. Outcome of patients hospitalized for COVID-19 and exposure to angiotensin-converting enzyme inhibitors and angiotensin-receptor blockers in France: results of the ACECoV study. Fundam Clin Pharmacol Published Online First: 28 October 2020. https://doi.org/10.1111/fcp.12613.

10. Lee KJ, Carlin JB. Multiple imputation for missing data: fully conditional specification versus multivariate normal imputation. Am J Epidemiol. 2010; 171:624-32. https://doi.org/10.1093/aje/kwp425.

11. Haukoos JS, Lewis RJ. The propensity score. JAMA. 2015;314:1637-8. https:// doi.org/10.1001/jama.2015.13480.

12. Thomas LE, Li F, Pencina MJ. Overlap Weighting: A Propensity Score Method That Mimics Attributes of a Randomized Clinical Trial. JAMA Published Online First: 5 May 2020. https://doi.org/10.1001/jama.2020.7819.

13. Li F, Thomas LE, Li F. Addressing extreme propensity scores via the overlap weights. Am J Epidemiol. 2019;188:250-7. https://doi.org/10.1093/aje/kwy201.

\section{Publisher's Note}

Springer Nature remains neutral with regard to jurisdictional claims in published maps and institutional affiliations.

Ready to submit your research? Choose BMC and benefit from:

- fast, convenient online submission

- thorough peer review by experienced researchers in your field

- rapid publication on acceptance

- support for research data, including large and complex data types

- gold Open Access which fosters wider collaboration and increased citations

- maximum visibility for your research: over $100 \mathrm{M}$ website views per year

At BMC, research is always in progress.

Learn more biomedcentral.com/submissions 